\title{
Crohn's Colitis with Perianal Disease Complicated by Collagenous Colitis: Discourse on Management Options
}

\author{
Talha A. Malik ${ }^{a}$ Shajan Peter ${ }^{a} \quad$ Nirag Jhala $^{b}$ Alexandra M. Gutierrez ${ }^{a}$ \\ Divisions of a Gastroenterology/Hepatology and ${ }^{b}$ Gastrointestinal Pathology, University of Alabama at \\ Birmingham, Birmingham, Ala., USA
}

\begin{abstract}
Dear Sir,
Crohn's disease (CD) and collagenous colitis (CC) are rarely seen together in clinical practice and when they are, they may present a management challenge. We describe the case of a patient with perianal CD unable to take steroids whose clinical course was complicated by the development of CC. A brief review of the topic follows the case presentation.
\end{abstract}

\section{Case Presentation}

A 59-year-old Caucasian woman with a longstanding history of Crohn's colitis with perianal disease received several traditional and biological immune modulators over the course of many years for recurrent increased clinical and mucosal

Dr. Gutierrez is on the speaker's bureau and a consultant for Abbott Pharm and UCB, and is a recipient of unrestricted educational grants from Abbott, Centocor, UCB and Proctor \& Gamble.

The abstract of this article was selected for poster presentation at the American College of Gastroenterology's 74th Annual Scientific Meeting (ACG2009), San Diego, Calif., USA. disease. She also had a history of depression and had undergone trials of several mood stabilizers over the years.

The patient was being maintained in clinical remission on a TNF blocker when she developed new onset perianal pain with discharge as well as increased diarrhea for which endoscopic and surgical evaluation was scheduled. An active perianal fistula was confirmed with a probe (fig. 1). Flexible sigmoidoscopy performed after seton placement into the fistula revealed a completely normal colonic mucosa to the level of the splenic flexure except for a minute area of inflammation at the anorectal junction where biopsies were taken. The pathology report suggested evidence of subepithelial accentuation of collagen band with increased chronic inflammation (fig. 2a, b). A subsequent colonoscopy performed for complete colonic mucosal evaluation also did not reveal any endoscopic disease, however, random colonic biopsies taken during the procedure confirmed the subepithelial accentuation of collagen band with increased chronic inflammation throughout the colon, therefore establishing a diagnosis of concomitant CC in the patient (fig. 3).

The patient had a history of severe acute steroid psychosis in the past and therefore budesonide was not an option. She had a remarkable and almost immediate response to a trial of bismuth subsalicylate with Imodium and the diarrhea abated. She was continued on the TNF blocker for treatment of her fistulizing CD and to maintain colitis in remission.

\section{Discussion}

$\mathrm{CD}$ is a transmural inflammatory process, first described by Crohn and colleagues in 1932, that can affect any part of the intestinal tract and may be classified according to disease behavior and the region affected $[1,2]$. Crohn's colitis with perianal disease is a debilitating form of CD [2]. CC is a slightly less prevalent inflammatory disease of the intestinal tract, first described in 1976, that penetrates only to the colonic submucosa and is usually characterized by a much more benign course [3]. CD is equally distributed between men and women whereas CC is more common in women and occurs at an older age [4-6]. CD and CC are both variably hypothesized to develop in genetically predisposed individuals as a result of an abnormal immune response of the intestinal mucosa to a luminal agent $[1,2]$. More-

\section{KARGER}

Fax +4161306 1234 E-Mail karger@karger.ch www.karger.com
Talha A. Malik, MD

701 19th Avenue South, LHRB 409

Birmingham, AL 35233 (USA)

Tel. +1 205975 9808, Fax +1 2059341007

E-Mail tmalik@uab.edu 


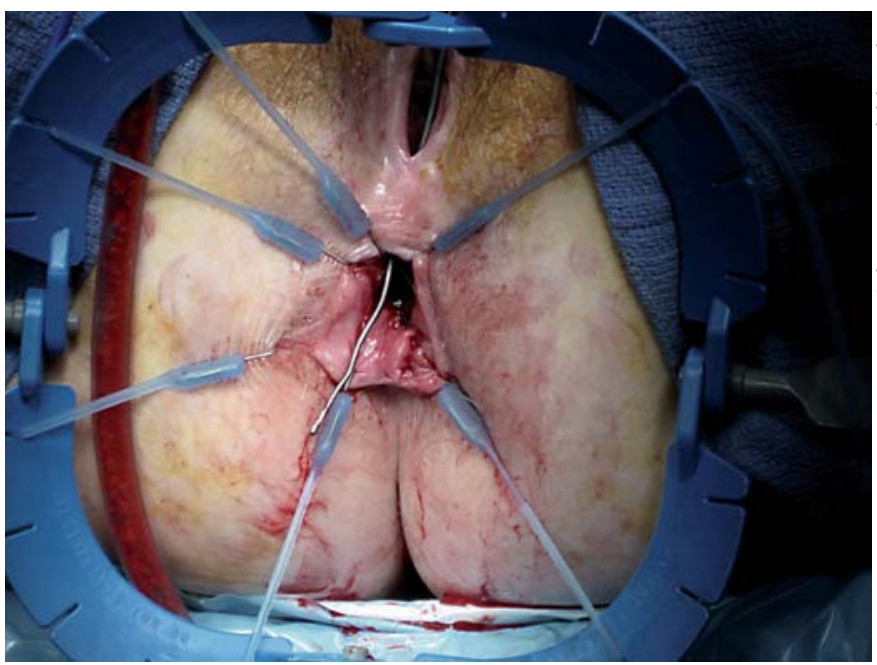

Fig. 1. Confirmation of the open perianal (rectovaginal) fistula with a probe prior to seton placement and flexible sigmoidoscopy.

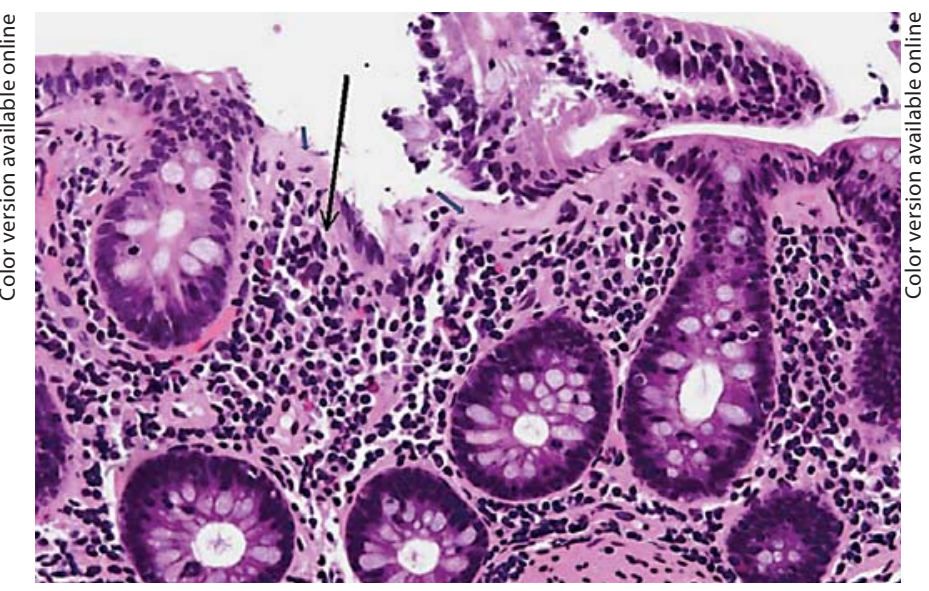

Fig. 3. Hematoxylin and eosin $(20 \times)$ stain of random mucosal biopsies taken throughout the colon on the subsequent colonoscopy demonstrates subepithelial accentuation of the collagen band (short arrows) with sloughing of epithelium and increased chronic inflammation (long arrow).
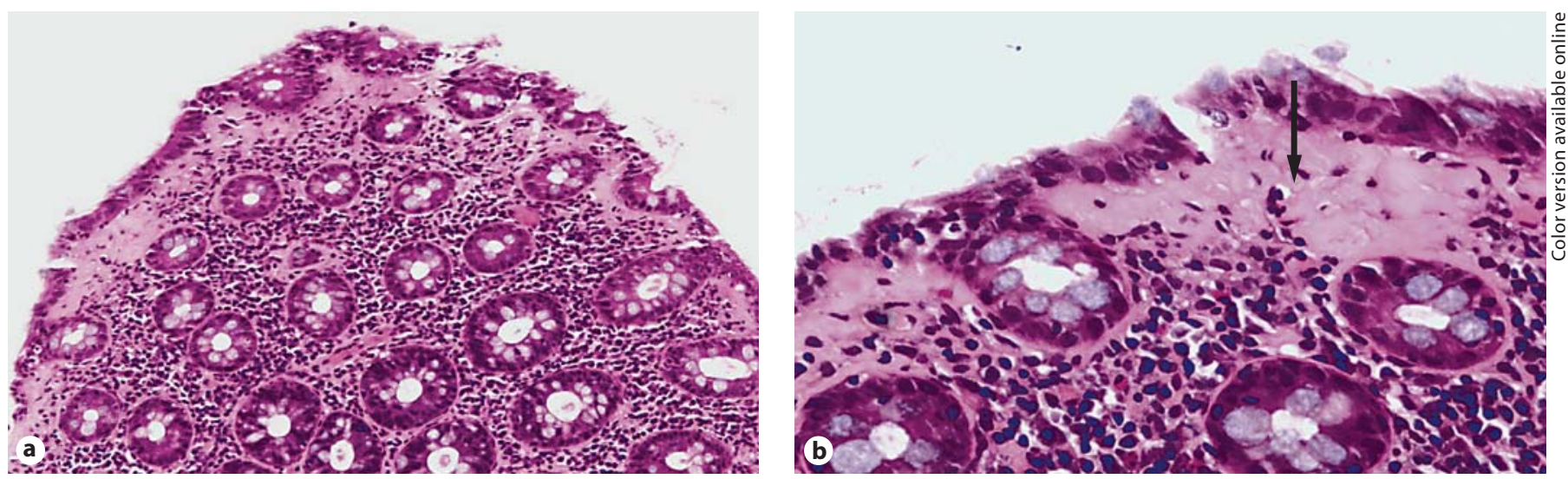

Fig. 2. Hematoxylin and eosin stains of mucosal biopsies taken around the anorectal junction. a Lower $(10 \times)$ magnification demonstrates preserved crypt architecture with increased plasma lymphocytic infiltrate in addition to an accentuated subepithelial collagen band. b Higher $(60 \times)$ magnification reveals a dense subepithelial collagen band with entrapped capillaries (arrow).

over, the development of CC has been linked to several medications including some antidepressants as well as a few infectious agents such as Yersinia enterocolitica and Clostridium difficile. CC may regress spontaneously on withdrawal of the causative agent or fecal diversion [7].

The most reliable way to diagnose each of the two conditions is through mucosal biopsies $[3,5,8]$. They rarely present in the same patient and when they do, CC usu- ally progresses to $\mathrm{CD}[4,5,9]$. Treatment of patients who simultaneously have CD and CC may pose a challenge as maintenance treatment of CD is based on steroid-sparing immune modulator therapy whereas the most effective maintenance therapy for CC is steroid-based with budesonide being the drug of choice [5]. Other than removing the potential causative drug, therapies that have shown efficacy in treating patients with CC include antibiotics, mesalamine and sulfasalazine, bismuth subsalicylate, cholestyramine as well as Imodium $[5,10]$.

This is the first case describing development of CC in perianal tissue of a CD patient with active perianal fistulizing disease. There is a rare but established association of these two conditions suggesting, at least in some patients, a similar etiopathogenetic mechanism. 


\section{References}

1 Crohn BB, Ginzburg L, Oppenheimer GD: Regional ileitis: a pathologic and clinical entity. JAMA 1932;99:1323-1329.

-2 Silverberg MS, Satsangi J, Ahmad T, et al: Toward an integrated clinical, molecular and serological classification of inflammatory bowel disease: report of a Working Party of the 2005 Montreal World Congress of Gastroenterology. Can J Gastroenterology 2005; 19(suppl A):5-36.

3 Lindstrom CG: 'Collagenous colitis' with watery diarrhea - a new entity. Pathol Eur 1976;11:87-89.
4 Haque M, Florin T: Progression of ulcerative colitis to collagenous colitis: chance, evolution or association? Inflamm Bowel Dis 2007;13:1321.

5 Bohr J, Tysk C, Eriksson S, et al: Collagenous colitis: a retrospective study of clinical presentation and treatment in 163 patients. Gut 1996;39:846-851.

6 Pardi DS, Loftus EV Jr, Smyrk TC, et al: The epidemiology of microscopic colitis: a population-based study in Olmsted County, Minnesota. Gut 2007;56:504-508.
7 Beaugerie L, Pardi DS: Drug-induced microscopic colitis - proposal for a scoring system and review of the literature. Aliment Pharmacol Ther 2005;22:277-284.

8 O'Beirne JP, Ireland A: Progression of collagenous colitis to Crohn's disease. Eur J Gastroenterol Hepatol 2005;17:573-575.

$\$ 9$ Freeman HJ: Complications of collagenous colitis. World J Gastroenterol 2008;14:16431645.

10 Fine KD, Lee EL: Efficacy of open-label bismuth subsalicylate for the treatment of microscopic colitis. Gastroenterology 1998; 114:29-36. 